\title{
The Impact of Built Environment Characteristics on Energy Consumption Using Geographically Weighted Regression in Mashhad, Iran
}

\author{
Bita Rezaeian ${ }^{1}$, Mohammad Rahim Rahnama ${ }^{1}$, Jafar Javan ${ }^{1} \&$ Omid Ali Kharazmi ${ }^{1}$ \\ ${ }^{1}$ Ferdowsi University of Mashhad, Iran \\ Correspondence: Mohammad Rahim Rahnama, Ferdowsi University of Mashhad, Iran. E-mail: \\ Rahnama@um.ac.ir
}

Received: June 7, $2017 \quad$ Accepted: July 12, $2017 \quad$ Online Published: September 29, 2017

doi:10.5539/jsd.v10n5p198 URL: https://doi.org/10.5539/jsd.v10n5p198

\begin{abstract}
Concerns over rising fuel consumption have prompted research into the influences of built environments on travel behavior. On the basis of data from origin-destination(OD) travel survey data of Mashhad (74287 trip data in 2011) and using Geographically Weighted Regression, socio-demographic characteristics, are shown to be strongly and positively associated with the fuel consumption per capita (car ownership elasticity $=0.347878$ ); we also found a positive association between distance to center and designs that are not pedestrian friendly with fuel consumption (average block size $=0.147489$, distance to center $=0.334953$ ) Although the study demonstrates a moderately strong negative elasticity between population density and the fuel consumption(population density = -0.259335). It suggests that the largest energy consumption reductions would come from creating compact communities which have land-use diversity and more walkable areas with pedestrian cycling infrastructure around all of the stations along transit lines.
\end{abstract}

In order to enhance a sustainable urban plan, the socio-economic driving factors should be considered as one of the main element of energy consumption as well.

Keywords: built environment, energy consumption, GWR

\section{Introduction}

With the growth in automobile use and increase in daily vehicle miles traveled (VMT), concerns over fuel consumption, energy prices, and congestion have turned research into the influences of built environment factors on motorized travel. Not only is the transport sector of Iran one of the largest energy consumers and sources of $\mathrm{CO}_{2}$ emissions, but also it is one of the fastest growing consumers of energy and producers of $\mathrm{CO}_{2}$ : other sectors are experiencing either stabilization or decline (Statistics Iran, 2016).

The transport sector must try to achieve the energy consumption reduction which targets to be more sustainable (Hickman, Headicar, \& Banister, 2009; Hickman, Ashiru, \& Banister, 2010).The built environment variables at origin and destinations are key factors for complexity of decisions for making travel, vehicle type choice, mode choice (such as private car, public transportation and non-motorized modes), travel time, distance and corresponding energy consumption which are result of traveler decisions that associate vehicle ownership and travel activities(Ewing \& Cervero, 2010).

We use an extensive data source, the origin-destination(OD) travel survey data of Mashhad (74287 trip data in 2011) which contains traveler characteristics, trip information, as well as vehicle characteristics. These data are aggregated to the 253 traffic regions at travel origin. The urban form variables are collected from major data sets of Mashhad Department of Planning (MDP). etc.

A large number of studies have examined the impact of Built Environment Characteristics on Energy Consumption, but very rarely consider the whole bundle of factors simultaneously. There is no any study employing location-specific output produced by GWR which used to visualize spatial variations in regression diagnostics and model parameters within a study area. Maps generated from GWR analysis play a key role in exploring and interpreting how statistical relationships and their significance alter over space. 


\section{Material Studied}

There is a considerable and growing body of research that investigates the relation between the built environment characteristics and travel behavior (Mitchell \& Rapkin, 1954; Cervero, 1996; Banister, 1997; Newman \& Kenworthy, 1999; Crane, 2000; Ewing and Cervero, 2001 \& 2010; Stead, 2001). Some researchers, showed that land use variables weakly affect the travel behavior (Boarnet \& Sarmiento, 1998; Giuliano \& Small, 1993). Others, including Krizek (2003) and Shen (2000), found that changing the built environment may lead to change in the travel behavior.

There is certainly little consensus within the body of literature as to the relationship between the built environment and the energy consumption (Anderson, Kanaroglou, \& Miller, 1996). For developed countries' research findings, the built environment characteristics have been considered as one of the main drivers of the energy consumption (Williams, Burton, Jenk, 2000). Brian (2008) did a study of 45 cities in the US, found that cities with low urban and population densities consumed more energy. Schweitzer and Zhou (2010) studied 80 metropolitan areas in the US and identified the same result as Brian. Many empirical studies in developed case studies have already found that urban planning has profound effects on energy consumption (Cervero, 1995; Levinson \& Kumar, 1997; Barter, 2000).

Some are more careful and suggest that urban form factors are, at most, playing a limited role. Other factors, such as income, are more important in affecting the travel behavior. The increasing diversity of vehicle type holdings and the growing vehicle tenure have expressive impact on the transportation energy consumption and air pollution. Bhat and Sen's analysis (2006) and Fang (2008) examined several different kinds of variables such as socio-demographics characteristics and residential location of household variables. Although both of them have significant influences on the travel behavior but what is related to the built environment is that households located in dense area have a disinclination for pickup trucks. With respect to the vehicle type choice, Cao, Handy and Mokhtarian (2006) found that the built environment moderately affect vehicle choice. Musti, Kortum, and Kockelman (2010) specified that closer distance to CBD was associated with more fuel efficient vehicle and lower vehicle ownership.

Frank, Stone and Bachman (2000), examined the relationship between land-use diversity, transportation mode choice, and the energy consumption in Washington. They used the data of residents' travel in the Puget Sound region. They determined fuel consumption from driving behavior and land-use data comprising distance between work and residential location, population and employment and block density. The result revealed that density had a negative impact on energy consumption; while, the distance to work has a positive relationship with the issue. Susilo and Stead (2012) using data from the Dutch National Travel Survey found the same but more precise result that individuals who live in very produce lower emissions per trip than those who live in less urbanized areas. This is probably due to the higher use of public transport and non-motorized modes in dense areas. They also found that residents of all types of urban area (except residents of very highly urbanized areas) produce relatively the same $\mathrm{CO} 2$ emission. They justified this similarity with tendency to make more non-work visit by Individuals who live in more urbanized than those who live in less urbanized areas. Under a compact development, where there are more alternative for travelers to use different transportation modes, the percentage of individuals using automobiles is decreasing, which reduces the energy consumption (Nam, Lim, \& Kim, 2012)

However, other studies have realized that the effect of density is modest. Crane and Crepeau (1998) argued that density was associated with quality and quantity of public transportation service and the travel behavior was related to cost variables, for example travel price and time. Frank, Bradley, Kavage, Chapman and Lawton (2008) investigated the relationship between travel time, costs, land-use diversity and trip chaining patterns. The results demonstrate that travel time is the most important variable. In addition to the individual vehicle choice and the transportation mode choice, driving patterns are related to land-use and also affect vehicle emissions and fuel consumption. For example, Brundell-Freij and Ericsson's study (2005) by using a data set of over 14,000 driving patterns registered in actual traffic, examined The relationship between driving patterns and vehicle, the driver and the traffic environment variables. The most important effect was specified for the variables describing the street environment including density of junctions controlled by the traffic lights, speed limit and neighborhood type. A relatively large effect was determined for car performance. The average speed systematically decreases for all street types, whereas stop time systematically increases on arterials for elderly drivers. The results have implications for the assessment of environmental effects through appropriate street categorization in emission models, as well as the possible reduction of environmental effects through better traffic planning and management, driver education and car design. 
Automobile ownership plays a pivotal role in examining vehicle use, consumption and determining traffic congestion. Cao, Mokhtarian and Handy (2007a) use data of 688 respondents who changed their residential locations over the previous year to find out the relationship between socio-economic factors and the built environment characteristics with SEM analysis. They identified that some built environment indexes such as household size of dwelling and living in areas with land-use diversity play rather modest role in car ownership. These authors (2007b) did a cross-sectional analysis. It should be noted that the finding is in contrast with the previous ones which showed that the built environment characteristics and car ownership were correlated because of self-selection. Jahanshahi and Jin (2016) used a new latent categorization approach in structural equation modelling (SEM) to achieve new vision into the impact of the built environment characteristics upon travel behavior using UK National Travel Survey data. They determined that no-car owning households with no-car ownership tenure generally tend to travel shorter distances, the influence of car ownership on travel differs across areas. Significant variations in influences also exist for the majority of the socio-economic characteristics and on all travel purposes. They indicated that the main challenges for professionals working towards sustainable transport solutions are to do with developing effective planning and design measures in the Medium urban areas in order to enhance the impact of the built environment on the travel choices.

For developing countries' case studies, some urban studies assumed that the design of the built environment affects the domestic energy consumption of both urban uses and transportation (Holden \& Norland, 2005)., some others showed that high density in the neighborhood area would reduce the fuel consumption because of the decrease in travel distance and car ownership (Brownstone \& Golob, 2009). Ho and Yamamoto (2011) examined the car ownership by using attitudes and preferences to control for self-selection effects. The residential location relative to central business district (CBD) was established significant effects on the travel behavior. Yamamoto (2009) examined the influence of the built environment on making trip in Taipei, Taiwan. They proved that density has a negative effect on the number of vehicle tenure, whereas it has a positive impact on the amount of trip making. T. Osman, Arima, Divigalpitiya and M. Osman (2016) investigated the effect of the built environment and socioeconomic driving factors on the fuel consumption through a case study of the Cairo metropolitan region, Egypt using Structural equation modeling (SEM). The results affirmed that household income and the family size especially number of adults as driving factors increase the energy consumption but in contrast with the other studies population slightly affect the fuel consumption as well as eco-friendly driving factors. The study findings suggest that the design of the built environment should be related to the socio-economic characteristics to control the fuel consumption in developing regions.

In summary, a large number of studies presented in a variety of literature have examined the relation between built environment, travel behavior and energy consumption. The regular data difficulties, nevertheless, caused that the existing studies zoom in one or several of the possible influences out of the group of known factors such as travelers' socio-demographic profiles, accessibility, mode choice, vehicle type choice, car ownership, built environment characteristics and travel purpose, but few studies consider the set of factors simultaneously. In addition to the best of the authors' knowledge, there is no any study employing location location-specific output produced by GWR which used to visualize spatial variations in regression diagnostics and model parameters within a study area. Maps generated from GWR analysis play a key role in exploring and interpreting how statistical relationships and their significance vary over space.

\section{Area Descriptions}

Mashhad is the second metropolitan of Iran. It is located in the northeast of the country with area of about $330 \mathrm{~km}^{2}$ (127 sq. mi). Its population was approximately 3,300,000 at the 2016 census.

The master data set includes the following components: consumption Information and built environment variables. We also incorporate controls for travelers' socio-demographic characteristics, which without them, the findings would be biased.

In the present research the data are collected from multiple sources. The primary data source is the OD travel survey data of Mashhad (74287 trip data in 2011) which contains traveler characteristics, trip information, as well as vehicle characteristics. These data are aggregated to the 253 traffic regions at the travel origin. The urban form variables capture five aspects of land use patterns including density, diversity, design, destination accessibility as well as distance to transit (Ewing \& Cervero, 2010). To calculate the built environment variables at origin levels, data are collected from major data sets: Mashhad Department of Planning (MDP), Mashhad Metropolitan organization (BMO), Mashhad. Census, and Mashhad Transit view. The built environment variables at the travel origin are defined in 253 traffic regions. The energy data are derived from travel data [vehicle mile travelled using origin destination data, mode choice, vehicle type choice and driving patterns] since they are not available in OD 
travel survey. (Figure 1)

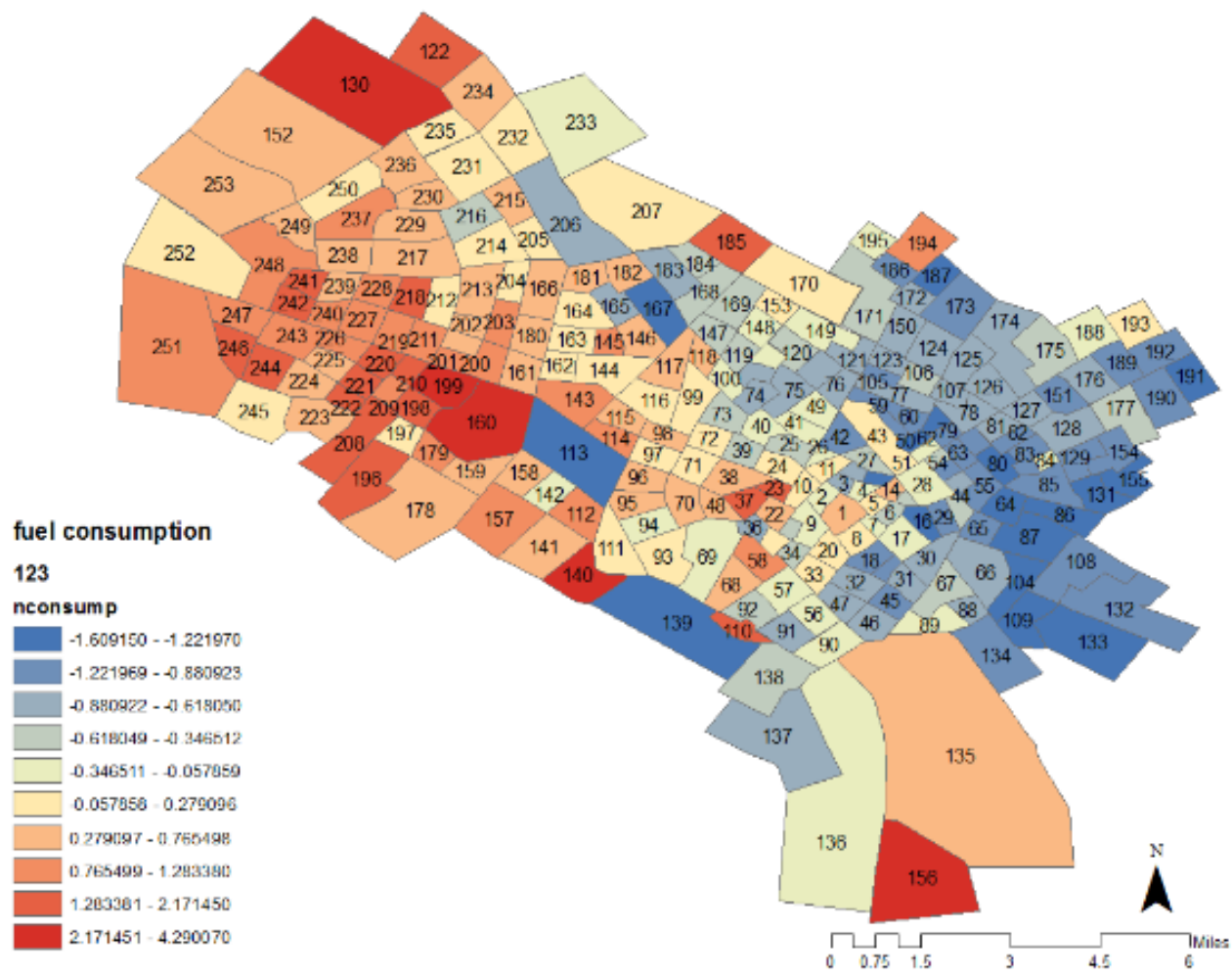

Figure 1. Map of the fuel consumption sample distribution. The energy data are provided by (VMT (Vehicle Mile Travelled using origin destination data), mode choice, vehicle type choice and driving patterns)

After merging all the components, the specific variables of the master data set are indicated in table 1 .

Table 1.the specific variables of the master data set

\begin{tabular}{lll}
\hline & Density & \multicolumn{1}{c}{$\begin{array}{l}\text { Population density } \\
\text { Employment density }\end{array}$} \\
\cline { 2 - 3 } Built environment variables & Diversity & Land use mixed \\
\cline { 2 - 3 } & Design & Average block size \\
\cline { 2 - 3 } & Destination accessibility & Street density \\
& & Distance to center \\
\cline { 2 - 3 } & Distance to transit & Bus-line coverage \\
\hline \multirow{2}{*}{ Socio-Demographic characteristics } & Income & \\
& Car ownership & \\
\hline Consumption & Fuel consumption & \\
\hline
\end{tabular}

\section{○ Density}

Population density and employment density at the region level are applied in this research. Figure $3 \mathrm{a}, \mathrm{b}$ with the graduated color map displays population density and employment density of each region. Region-based population and employment data collected from the Mashhad Census (2011). The values were calculated by dividing the amount of population, housing, and employment by area (acre) of region.

○ Diversity 
Land use data are originally given from the Mashhad data set (2011), land use types including residential, commercial, and office of each property.

$$
\text { Land use mix }=((-1) / \ln n) * \sum_{i=1}^{n} p i \ln p i
$$

Where

$p i$ is the percentage of land use type $i$ of the total land area;

$n$ is the number of different land use types

The land use mix ranges from 0 to 1 and captures how evenly the square footage

of commercial, residential, and office floor area is distributed within each trip origin's

region. 0 represents a single land use environment, such as purely residential

neighborhood. 1 represents the perfect even distribution of square footage of across

all three land uses. The higher the value of land use mix index,

The more balanced land use will be (Frank, Martin, \&schemed, 2004). Figure 3c.

\section{$\circ \quad$ Design}

In this research design is measured by average block size in the traffic region. Figure 3d.

\section{- Destination accessibility}

The street network density is calculated in traffic regions as first factor of destination accessibility. Figure3e.

Regional accessibility is simply distance to the central business district (CBD). Here CBD is defined based on merging population and employment hotspots using GIS10.4. spatial statistics tools/mapping cluster. Figure 3f.

○ Distance to transit

Distance to transit is measured as the distance from each trip origin to the nearest bus stop and metro stop. Figure $3 \mathrm{~g}$.

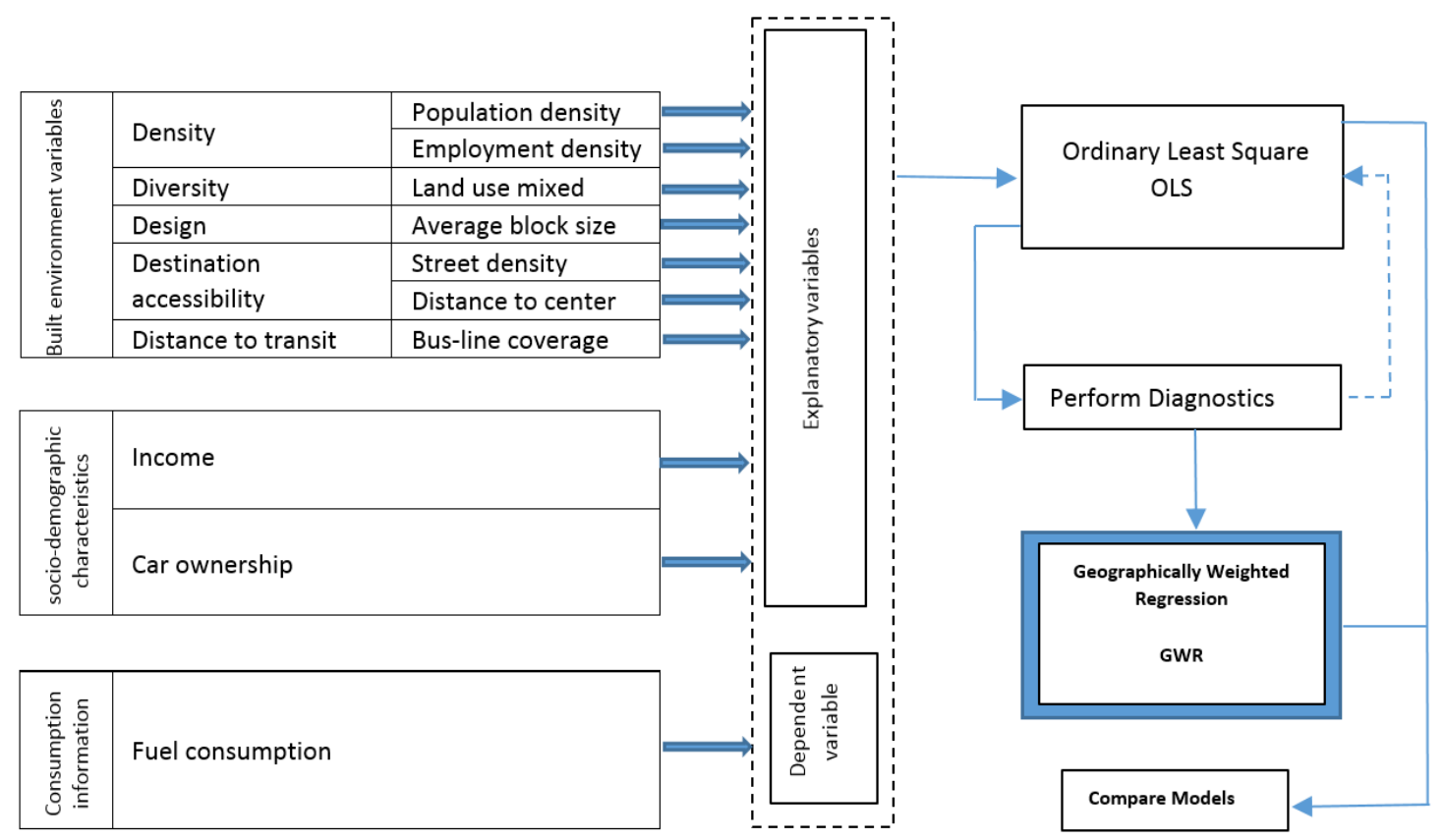

Figure 2. Data processing and analysis work flow 


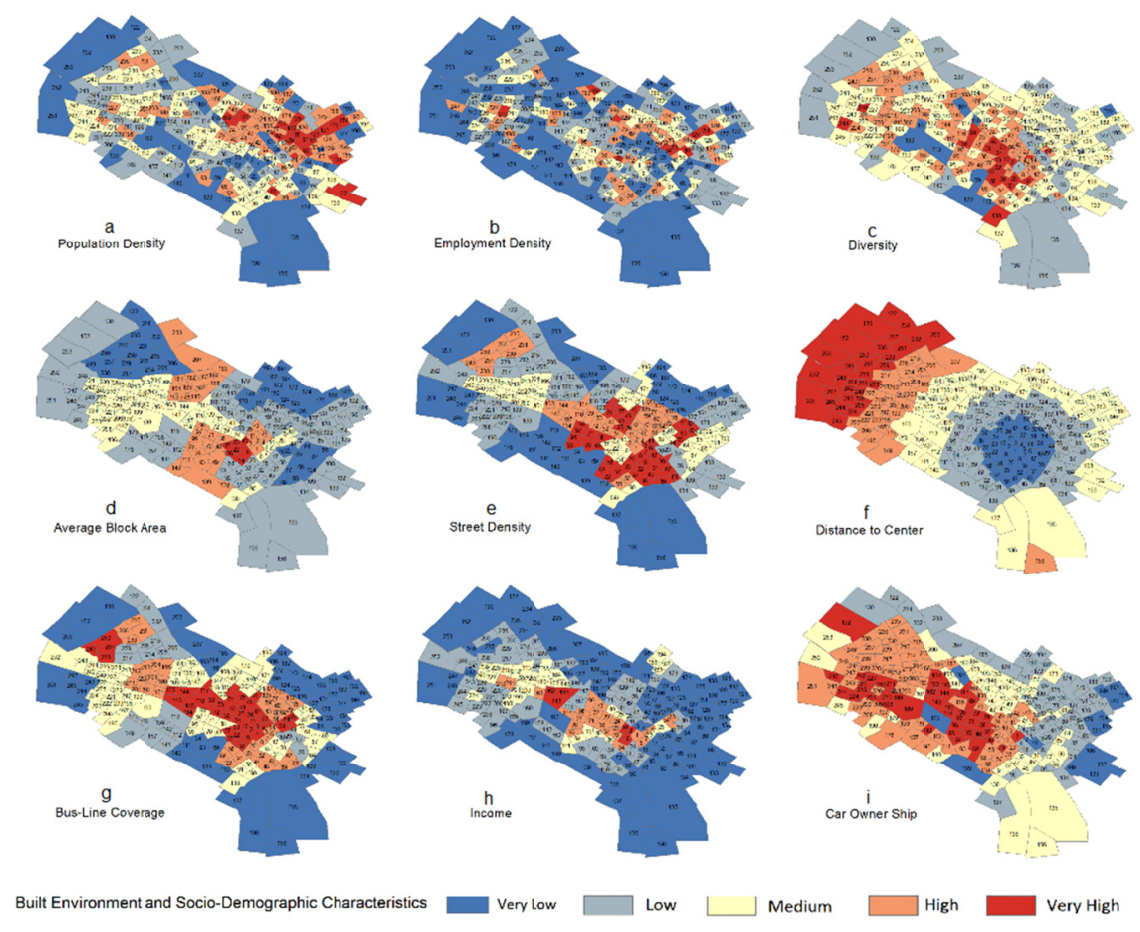

Figure 3. Map of the built environment and socio-demographic characteristics sample distribution

\section{Methods}

The model is helped by the Regression analysis so as to examine and explore spatial relationships as well as to explain the factors behind the observed spatial patterns. Ordinary least squares (OLS) could be set as a proper start point for all spatial regression analyses which supports a global model of variables or processes to be understood; in order to represent the process, the model designs a single regression equation. One of various spatial regression techniques is geographically weighted regression (GWR) which is used in geography and other disciplines increasingly. Fitting a regression equation to every feature in the dataset, GWR provides a local model of variables or processes through it. In case the methods are used properly, they provide powerful and reliable statistics to examine and estimate linear relationships. Linear relationships are either positive or negative. (Mitchell, 2005; Ciotoli, 2016).

One of the advantages for it is that the mode is based on the traditional regression framework. Another is that it combines local spatial relationship into the regression framework instinctively and specifically( Fotheringham, Brunsdon, \& Charlton, 2003).

\subsection{Ordinary Least Squares (OLS)}

Global OLS and spatial GWR regressions are used to model the spatial relationships between the built environment data and the fuel consumption. Particularly, the regression model includes a dependent variable and some explanatory independent variables. GWR is taken to be a complementary approach to the energy consumption spatial regression modelling in this study for which GWR 4.0 software is used. Since GWR outputs are locally specified, they are integrated with ESRI ArcGIS software in order to analyze patterns, clusters, visualizations and mappings (Krivoruchko, Gribov, \& Krause, 2011; Krivoruchko, 2011). Furthermore, a supplementary software for ARC GIS for which GeoDa software is used. Afterwards, all data are standardized so that the problems caused by different measurement units are minimized. The most popular of all regression techniques is OLS is as it creates a single regression equation to illustrate the progress. The procedure of finding the optimal global OLS regression model is a difficult one; this is more accentuated when several possible explanatory variables are present (Hamilton, 1992).

In this study, the "Spatial Statistics Tool" of ArcGIS 10.4 is used to perform paper OLS. The OLS tool in ArcGIS provides the akaike's information criterion (AIC) as additional information regarding the performance of the model and a map layer of model residuals. 
The set of used statistical parameters as well as respective critical values are presented in the following:

- Values of Multiple R-Squared and Adjusted R-Squared are measures of model performance. Possible values range from 0.0 to 1.0. The Adjusted R-Squared value is always a little lower than the Multiple R-Squared value, since it reflects the complexity in the model. An adjusted R2 of 0.50 or higher is acceptable (Mitchell, 2005).

- Each explanatory variable in the model, namely the coefficient, probability or robust probability, as well as variance inflation Factor (VIF), is assessed. Each explanatory variable's coefficient reflects the strength and the type of relationship the explanatory variable has with the dependent variable. The Coefficient represents the strength and type of relationship between each explanatory variable as well as the dependent variable (Asterisk $(*)$ indicates a coefficient which is statistically significant $(\mathrm{p}<0.01))$. Multi-collinearity is measured by the VIF in which the extent of the increase is determined; the correlations among explanatory variables is the reason for the increase. Some correlations among two or more explanatory variables are possible in the models benefitting from them, which result in a highly-unstable correlation coefficient (Kleinbaum, Kupper, Muller, \&Nizam,1998). A high value of VIF indicates a high collinearity. However, the large values of VIF ( $>7.5)$ indicate redundancy among explanatory variables.

Assessing the model's significance is the next step. Measures of overall model statistical significance are the Joint F-Statistic and Joint Wald Statistic, respectively. In case the Koenker (BP) statistic (see below) is not statistically significant, the Joint F-Statistic is trustworthy. Provided the Koenker (BP) statistic is significant, the Joint Wald Statistic had better be examined so that overall model significance is determined. The fact that the explanatory variables in the model are ineffective is a proof of the null hypothesis for both of these tests. Ap-value (probability) of smaller than 0.05 indicates a statistically significant model when confidence is 95 percent (Bennett, L \& D'Acosta, 2010).

- Fourthly, model bias is assessed. The Jarque-Bera statistic indicates whether the residuals (the observed/known dependent variable values minus the predicted/estimated values) are normally distributed or not. As long as the residuals are not normally distributed the model is biased. Nevertheless, biased residuals indicate model misspecification. The results of OLS are not trustworthy when the model is mis-specified (Kleinbaum et al., 1998; Jarque \& Bera, 1987). Techniques of Spatial autocorrelation could be applied to model residuals in order to determine whether model residuals indicate significant clusters (Dormann et al., 2007; Cliff \& Ord, 1972).

- Next is assessing stationarity. The Koenker (BP) Statistic (Koenker's studentized Bruesch-Pagan statistic) is a test to determine whether the explanatory variables in the model have a consistent relationship to the dependent variable in geographic space and in data space, respectively. The statistically-significant results of test, the robust coefficient standard errors and probabilities are consulted so as to assess the effectiveness of each explanatory variable (Mitchell, 2005).

GWR technique is often best used in regression models with statistically significant non-stationarity. Moreover, according to Qui and $\mathrm{Wu}$ (2013) initial confirmation of predictor variables to be statistically-significant through OLS regression is necessary. The abovementioned explanations are the main reasons to conduct an OLS regression prior to the GWR.

\subsection{Geographically Weighted Regression (GWR)}

A majority of the standard methods of statistical analysis which are employed in the social and environmental sciences are based on the basic assumptions of independence and homogeneity; the concepts are hardly advocated by spatially distributed observations and variables. Spatial dependence refers to the idea that locational proximity often leads to similarity of values when most demographic or socioeconomic variables are mapped, yet following Tobler's first law of geography saying "everything is related to everything else, however near things are more related than isolated ones" (Tobler, 1970).

GWR is the technique which is specifically designed to analyze spatial nonstationary; it is defined as the time when the origin and significance of relationships among variables vary from one place to another (Fotheringham, Brunsdon, \& Charlton, 2002). GWR is a locally spatial statistical technique which is used to examine how regression parameters and model performance differ across a study region (Gilbert \& Chakraborty, 2011).

GWR is exploited as a form of recent improvement so as to model spatially heterogeneous processes (Brunsdon, Fotheringham, \& Charlton, 1996; Fotheringham, 1997). GWR is based on the idea that parameters could be measured anywhere in the study region as a dependent variable and a set of independent variables which are calculated at places where the location is known. It might be expected that in case estimating parameters for a model at some location is desired, then closer observations should be more highlighted than the distant ones in the 
estimation (Fotheringham, Brunsdon, \& Charlton, 2009).

Compared to ordinary or global regression, GWR is part of various important assets for statistical analysis. Firstly, particular statistical tests could be benefitted from in order to assess the advantage of GWR approach so that the explanatory power of the set of regressions in the GWR as a whole is figured out and the results are compared to a single global regression model (Brunsdon, Fotheringham, \& Charlton, 1999). Secondly, the spatial changeability of the regression parameters could be analyzed so that it is determined whether specific statistical relationships with the dependent variable are truly non-stationary or do they vary significantly over space. Thirdly, using GWR is expected to provide error terms (residuals) which are considerably smaller and less spatially-dependent to the residuals of a comparable global regression model (Tu \& Xia, 2008). Finally, the output constructed by GWR which is location-specific is utilized to present spatial variations in regression in study area. GWR analysis-based maps may explore how statistical relationships and their significance vary over space (Gilbert \& Chakraborty, 2011).

Area preservation is ensured through a fixed kernel; thus,in spite of a change in the number of local observations in the kernel area, the area represented by each local equation remains constant (Brunsdon, Fotheringham, \& Charlton, 1998).Nonetheless, the number of observations within each kernel area remains the same in case an adaptive kernel is taken advantage of. The most appropriate selection is the adaptive kernel in case a highly irregular spatial distribution of the observations is possible (Fotheringham, Charlton, \&Brunsdon, 2001). In this study, the Gaussian fixed kernel type is adopted which is weighed continuously and gradually decreases from the center of the kernel yet never reaches zero. As the Gaussian kernel averts or mitigates the risk of having no data within a kernel, it is suitable for fixed kernels.

Traditionally, different methods are used to define the finest bandwidth value or the appropriate value of $\mathrm{n}$. The GWR algorithm in GWR4 software provides different methods for it including the Akaike Information Criteria (AIC) (Hurvich, Simonoff, \&Tsai, 1998; Akaike, 1974) and the Cross- Validation (CV) score procedure. Lower values of AIC indicate better model performance (Cleveland, 1979).

\section{Results}

\subsection{Preliminary Statistics}

Table 2 reports summary statistics for the average fuel consumption data at travel origin collected in the 253 traffic regions of Mashhad

Table 2. Detailed statistics for the average fuel consumption per each travel at travel origin. The statistics was calculated in the 253 traffic regions of Mashhad. Min, minimum value; Max, maximum value; Std.Dev., standard deviation

\begin{tabular}{llcccc}
\hline Variable & $\begin{array}{l}\text { Abbreviation name of } \\
\text { variable }\end{array}$ & Min & Max & Mean & St.Dev. \\
\hline $\begin{array}{l}\text { average fuel consumption per each travel at } \\
\text { travel origin }\end{array}$ & $\begin{array}{l}\text { Nconsump } \\
(\mathrm{MJ} / \mathrm{Km})\end{array}$ & 1.9 & 25 & 8.201083 & 3.915772 \\
\hline
\end{tabular}

Table 3 reports summary statistics of the proxy variables calculated for the built environment and socio-demographic characteristics at the 253 traffic regions of Mashhad. 
Table 3. Main statistics of the proxy variables to be considered under this study. The statistics was calculated in the 253 traffic regions of Mashhad. Min, minimum value; Max, maximum value; Std.Dev., standard deviation

\begin{tabular}{llllll}
\hline Variable & Abbreviation name of variable & Min & Max & Mean & St.Dev. \\
\hline Population density & Ndense & 0 & 380.787 & 132.355285 & 79.457992 \\
Job density & Ndenjob & -89.0633 & 214 & 8.530827 & 49.181424 \\
Land-use diversity & Ndiver & 0 & 0.86 & 0.413755 & 0.141529 \\
Average block area & Nblocarea & 3264.21 & 14113.9 & 6605.347352 & 2164.340543 \\
Street density & Nstdens & 34.53 & 267.58 & 178.993913 & 53.938756 \\
Distance to center & Ndiscen & 0 & 15.735 & 6.107945 & 3.8603 \\
Bus-line density & Nbusline & 2.83 & 208.94 & 67.609486 & 38.01368 \\
Average income & Nincom & 67 & 1422 & 337.201581 & 273.817867 \\
Average car ownership & Ncarown & 0 & 0.313 & 0.18534 & 0.06423 \\
\hline
\end{tabular}

\subsection{OLS Regression Model}

The actual field for all spatial regression analyses is provided by the OLS regression as it presents a global model of the variable or process for prediction; as the result, a single regression equation to illustrate the process is created. Firstly, in order to evaluate the effects of the built environment and socio-demographic characteristics on the fuel consumption in addition to testing for the possibility whether the effect of the predictor variables on the dependent variable varies continuously over space OLS regression was applied. In Table 5, the obtained results confirm the fact that the model provides explanations for approximately $55 \%$ of the variation in the explanatory variables. The model significance is assessed by the Joint F-Statistic and the Joint Wald Statistic. The Joint F-Statistic is reliable only when the Koenker (BP) (Koenker's studentized Breusch-Pagan statistic, BP) statistic is not statistically significant. In this case, the Koenker (BP) statistic is significant; therefore, the Joint Wald Statistic highlights a statistically significant model. Furthermore, the Koenker (BP) statistic determines whether the explanatory variables in the model have a consistent relationship to the dependent variable, both geographic space and in data space. As long as the model is consistent with the geographic space, the spatial processes which are presented by the explanatory variables have similar behavior everywhere in the study area (i.e. the processes are stationary). The variety of the relationship between the values predicted and each explanatory variable remain the same during changes in explanatory variable magnitudes when the model is consistent in data space (i.e. there is no heteroscedasticity in the model). In this case, the significance of the Koenker (BP) statistic indicates heteroscedasticity and/or non-stationarity of the model; hence, the model is a good candidate for Geographically Weighted Regression analysis. Table 5 reports the Jarque-Bera statistics and they indicate that residuals are non-normally distributed. Additionally, a statistically significant Jarque-Bera test may occur as long as a strong heteroscedasticity is present. Furthermore, the results obtained from the spatial autocorrelation test (Global Moran's I) reveal the fact that residuals are not spatially random yet they have significant clustering of high and/or low residuals (model under- and over-predictions).

The diagnostic coefficients are reported in Table 4. Important elements of the OLS regression are captured by them. Consistency of some explanatory variables (low Standard Error) are highlighted in the table; besides, NDENS, NBLOCAREA, NDISCEN and NCAROWN explain a low percentage of the total variance while the other explanatory variables explain a very low percentage of the variance are not significant in the OLS model (Robust Probability not significant); accordingly, the abovementioned data are not used as explanatory variables in the GWR regression model.

The obtained OLS regression equation is:

$$
\begin{gathered}
Y(N C O N S U M P)=0.000001-0.226026(N D E N S)+0.014865(\text { NDENJOB })+0.010354(\text { NDIVER })+ \\
0.147385(\text { NBLOCAREA })-0.002185(N S T D E N S)+0.365996(\text { NDISCEN })-0.053672(\text { NBUSLINE }) \\
-0.062613(\text { NINCOM })+0.431886(\text { NCAROWN })
\end{gathered}
$$

NDISCEN and NCAROWN content show the highest coefficients. The histogram of the regression residual displays that residuals are non-normally distributed while the Global Moran's I indicates that they are spatially auto correlated (Figure $4 \mathrm{a}$ and $\mathrm{b}$ ). 
Table 4. Coefficient diagnostic table of the OLS global regression model (*=statistical significant)

\begin{tabular}{llllll}
\hline Variable & Coefficient & StdError & Robust_t & Robust_Pr & VIF [c] \\
\hline intercept & 0.000001 & 0.042307 & 0.000017 & 0.999987 & ------ \\
NDENS & -0.226026 & 0.050302 & -4.624137 & $0.000008^{*}$ & 1.413650 \\
DENJOB & 0.014865 & 0.047328 & 0.457291 & 0.647882 & 1.251434 \\
NDIVER & 0.010354 & 0.053513 & 0.162456 & 0.871075 & 1.599905 \\
NBLOCAREA & 0.147385 & 0.061033 & 2.082344 & $0.038349 *$ & 2.081151 \\
STDENS & -0.002185 & 0.073724 & -0.028802 & 0.977039 & 3.036638 \\
NDISCEN & 0.365996 & 0.057584 & 6.460683 & $0.000000^{*}$ & 1.852597 \\
NBUSLINE & -0.053672 & 0.072459 & -0.936762 & 0.349799 & 2.933327 \\
NINCOM & -0.062613 & 0.058512 & -1.148314 & 0.251965 & 1.912810 \\
NCAROWN & 0.431886 & 0.058521 & 6.246539 & $0.000000 *$ & 1.913333 \\
\hline
\end{tabular}

Coefficient Represents the strength and type of relationship between each explanatory variable and the dependent variable.

Robust Probability (Robust_Pr): Asterisk $\left(^{*}\right)$ indicates a coefficient is statistically significant $(\mathrm{p}<0.01)$; if the Koenker

(BP) Statistic [f] is statistically significant, use the Robust Probability column (Robust_Pr) to determine coefficient significance.

Table 5. Main parameters of the Ordinary Least Squared regression model. DoF=Degree of Freedom; * indicates significance

\begin{tabular}{|c|c|c|c|}
\hline Parametr & Value & Probability & pvalue \\
\hline Number of Observation & 253 & & \\
\hline Multiple R-Squared [d]: & 0.565062 & & \\
\hline Adjusted R-Squared [d]: & 0.548954 & & \\
\hline $\begin{array}{l}\text { Akaike's Information Criterion (AICc) } \\
\text { [d]: }\end{array}$ & 530.442478 & & \\
\hline Joint F-Statistic [e]: & 35.077879 & $\operatorname{Prob}(>F),(9,243)$ degrees of freedom: & $0.000000^{*}$ \\
\hline Joint Wald Statistic [e]: & 461.175000 & $\begin{array}{l}\text { Prob(>chi-squared), (9) degrees of } \\
\text { freedom: }\end{array}$ & 0.000000 \\
\hline Koenker (BP) Statistic [f]: & 34.247596 & $\begin{array}{l}\text { Prob(>chi-squared), (9) degrees of } \\
\text { freedom: }\end{array}$ & 0.000081 \\
\hline Jarque-Bera Statistic $[\mathrm{g}]$ : & 994.404119 & $\begin{array}{l}\text { Prob(>chi-squared), (2) degrees of } \\
\text { freedom: }\end{array}$ & $0.000000^{*}$ \\
\hline
\end{tabular}



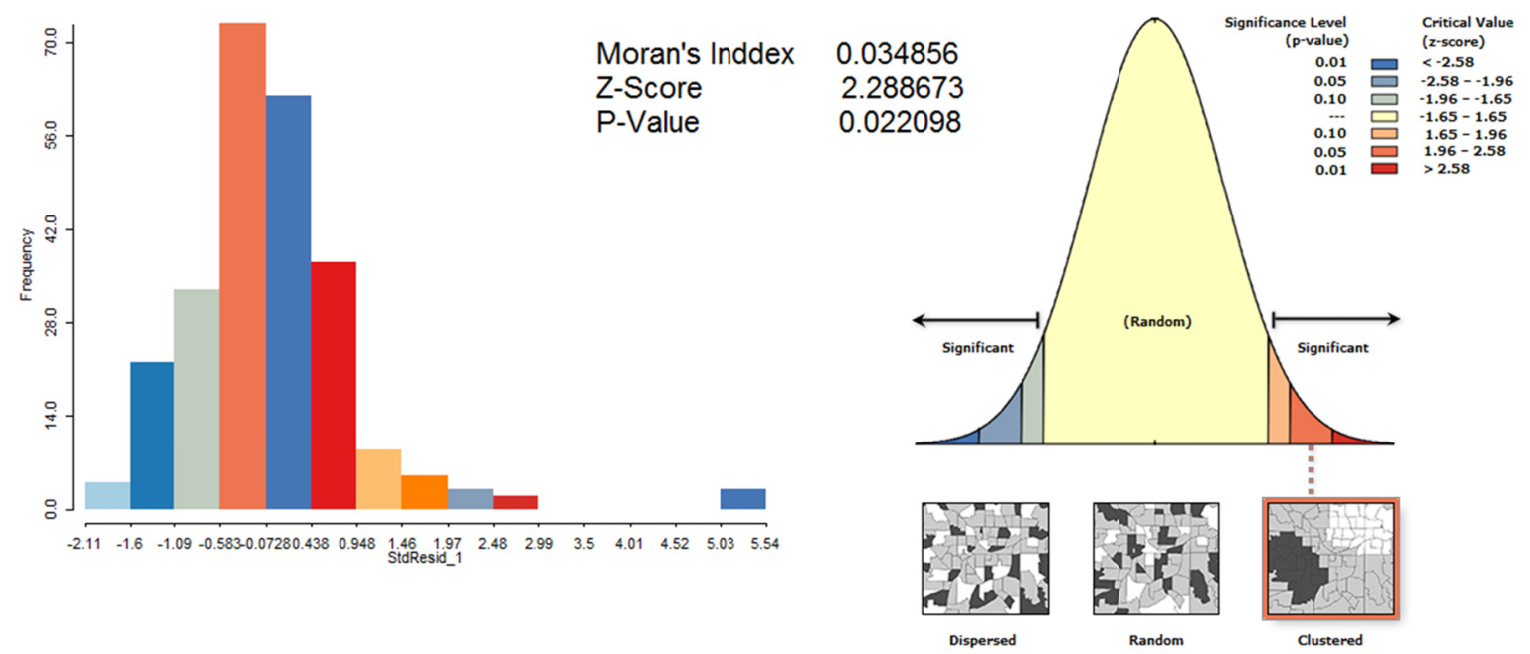

Figure 4. Histogram of the standardised residuals of the OLS (a) and the Morans'I autocorrelation test (b)

\subsection{Spatial Regression Model}

GWR is used to calculate a spatial regression model and it takes the relationships between the fuel consumption and population density, average block area, distance to center and average car ownership into account. The dataset (calculated values for 253 traffic regions of Mashhad) was developed through GWR4 software so that the spatial regression model is constructed. In order to analyze each local regression, the fixed Gaussian kernel type was used.

The main statistics of the overall GWR model parameters and local parameters are reported in Tables 6 and 7., One of the highlighted features of the GWR technique is presence of several sets of statistics, i.e. local relationships.

A high number of variances ( 2 adjusted $=0.786043$ ) are explained by the local spatial model. It illustrates a better fitting of observed y values with respect to the OLS model. Proper and weak prediction areas by GWR are indicated in the map of the Local R2 values (Fig.5)

Table 6. Main parameters of the GWR local model

\begin{tabular}{ll}
\hline varname & variable \\
\hline Bandwidth & 0.013749 \\
Sigma & 0.462072 \\
AICc & 407.915547 \\
R2 & 0.860135 \\
Adj. R2 & 0.786043 \\
\hline
\end{tabular}

Table 7. Main statistics of the coefficients of the explanatory variables for the GWR model. Robust STD, standard deviation; Min, minimum value; Max, maximum value; IQR, interquartile range

\begin{tabular}{lllllll}
\hline Variable & Mean & Robust STD & Min & Max & Median & IQR \\
\hline Intercept & -0.117166 & 0.485783 & -3.451680 & 9.292470 & -0.166559 & 0.655321 \\
ndens & -0.259335 & 0.246978 & -1.318693 & 0.814218 & -0.213850 & 0.333173 \\
nblocarea & 0.147489 & 0.193866 & -5.140496 & 3.420445 & 0.102647 & 0.261525 \\
ndiscen & 0.334953 & 0.367349 & -3.214466 & 6.838316 & 0.296055 & 0.495554 \\
ncarown & 0.347878 & 0.309343 & -2.803252 & 3.827869 & 0.339656 & 0.417304 \\
\hline
\end{tabular}




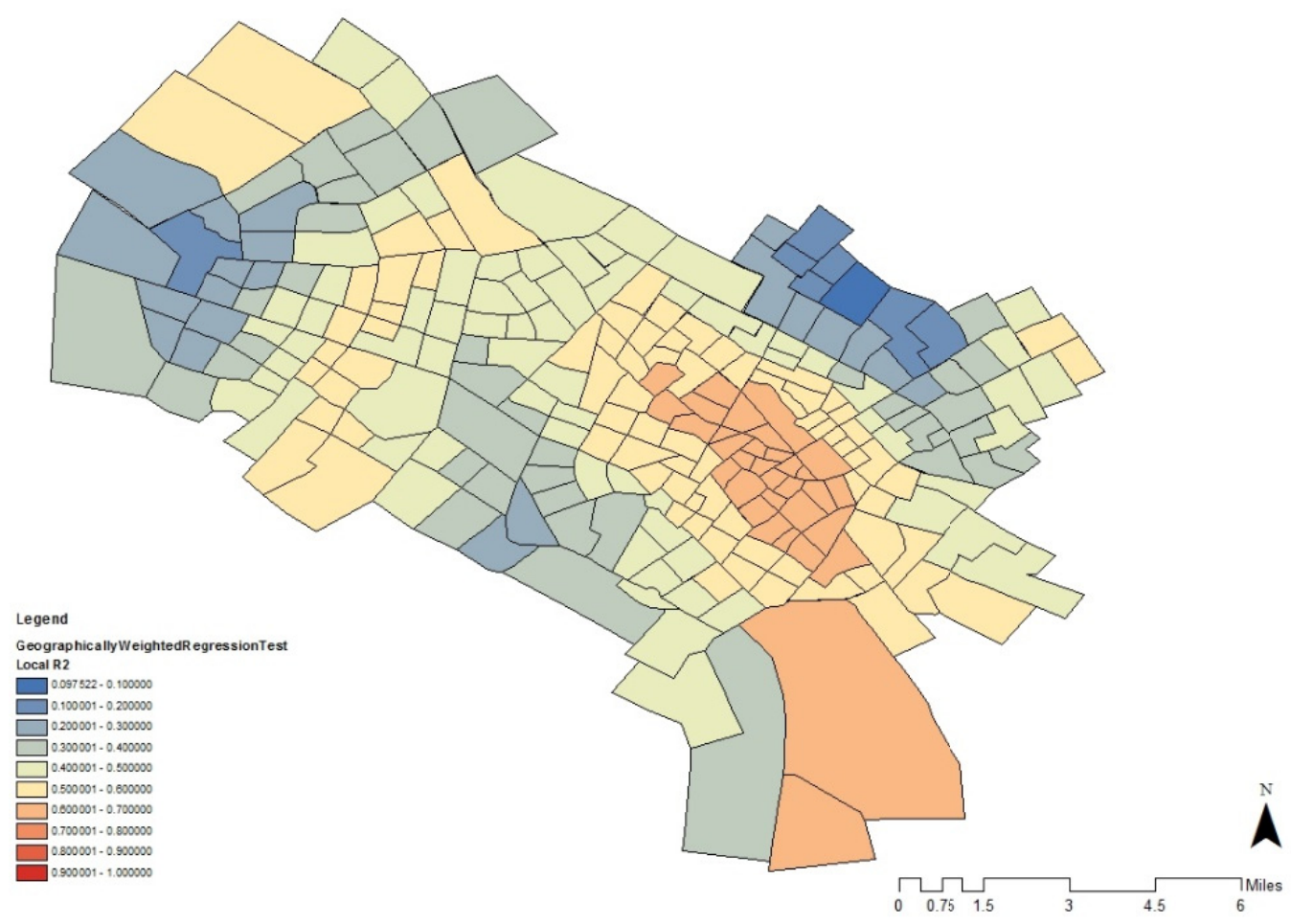

Figure 5. The map of the Local R2 values indicates where the GWR predicts well and where it predicts poorly

The map shows that this GWR model explains local relationships better (R2>0.5) in the central, south east and middle west of regions, The Local R2coefficients $(\mathrm{R} 2<0.5)$ appears slightly worse in correspondence of the south, north east and west regions.

Besides the model performance $(\mathrm{AIC}=407.915547)$ is better than that calculated by the OLS model $(\mathrm{AIC}=530.442478)$. The sigma value is the estimated standard deviation of the residuals. The smaller values are preferable [in this model, sigma $=0.462072$ is smaller than calculated by the OLS model. sigma $=0.6729310]$. The standardized residuals of the regression have a Gaussian distribution, confirming the good performance of the model, and the Morans'I autocorrelation test highlights that residuals are not spatially auto correlated. (Figure6).
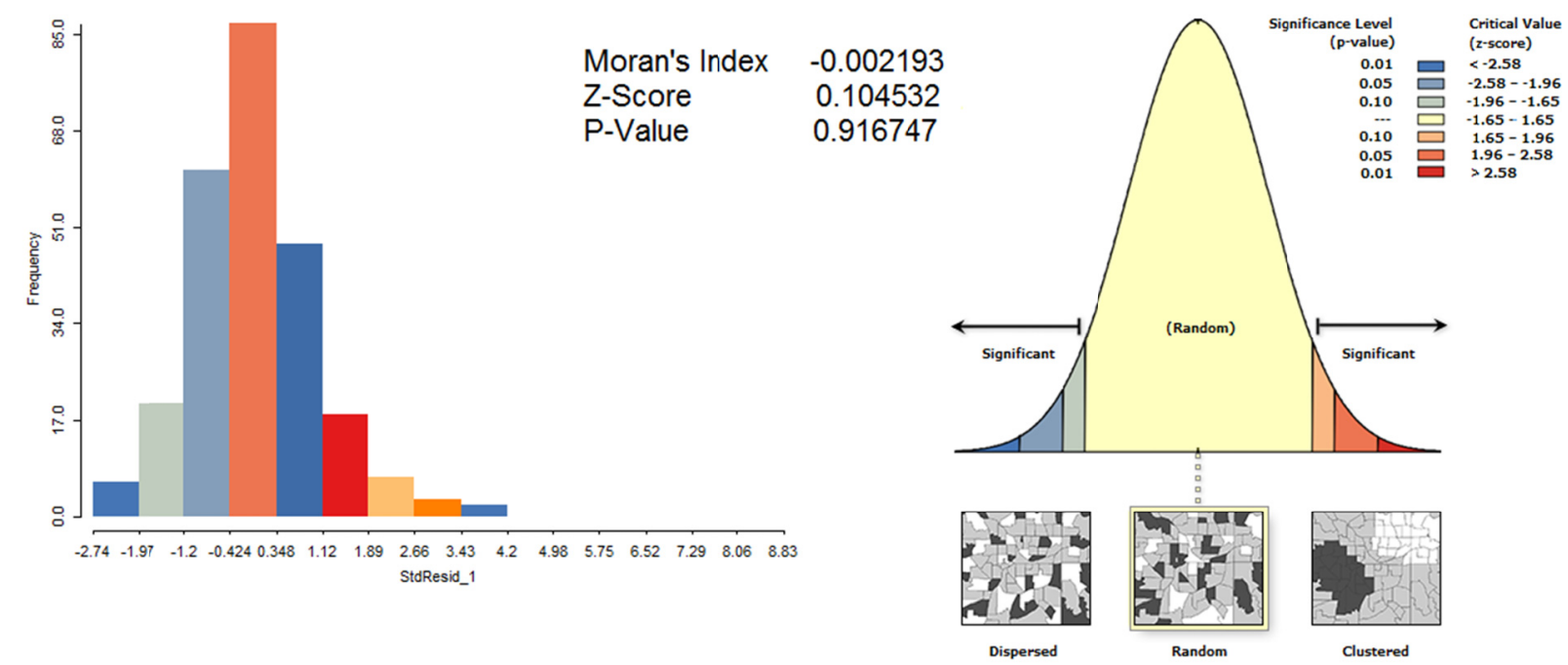

Figure 6. Histogram of the standardised residuals of GWR (a) and the Morans'I autocorrelation test (b) 
The ANOVA test is employed to compare the significance of the Global Residuals (OLS model) and the local residuals (GWR model), indicating the improvement provided by the GWR model (Table.8)

ANOVA test for the comparison of the OLS and GWR regression models.

Table 8. ANOVA test for the comparison of the OLS and GWR regression models

\begin{tabular}{lllll}
\hline ANOVA & SS & DF & MS & F \\
\hline Global Residuals & 111.213 & 248.000 & & \\
GWR Improvement & 75.828 & 82.266 & 0.922 & \\
GWR Residuals & 35.386 & 165.734 & 0.0214 & 4.317053 \\
\hline
\end{tabular}

The mean values of the coefficients calculated by the GWR model assure that the fuel consumption is positively related to the average block area, distance to center and average car ownership whereas population density negatively affects the fuel consumption across the study region. As the result shows, average car ownership and distance to center are probably the most significant factors controlling fuel consumption, the population density and the average of block size are ranked in lower grade. The model fitting was provided using a cross-validation graph that indicates a Root-Mean-Square Standardized and a Gaussian standardized error distribution (Figure 7).
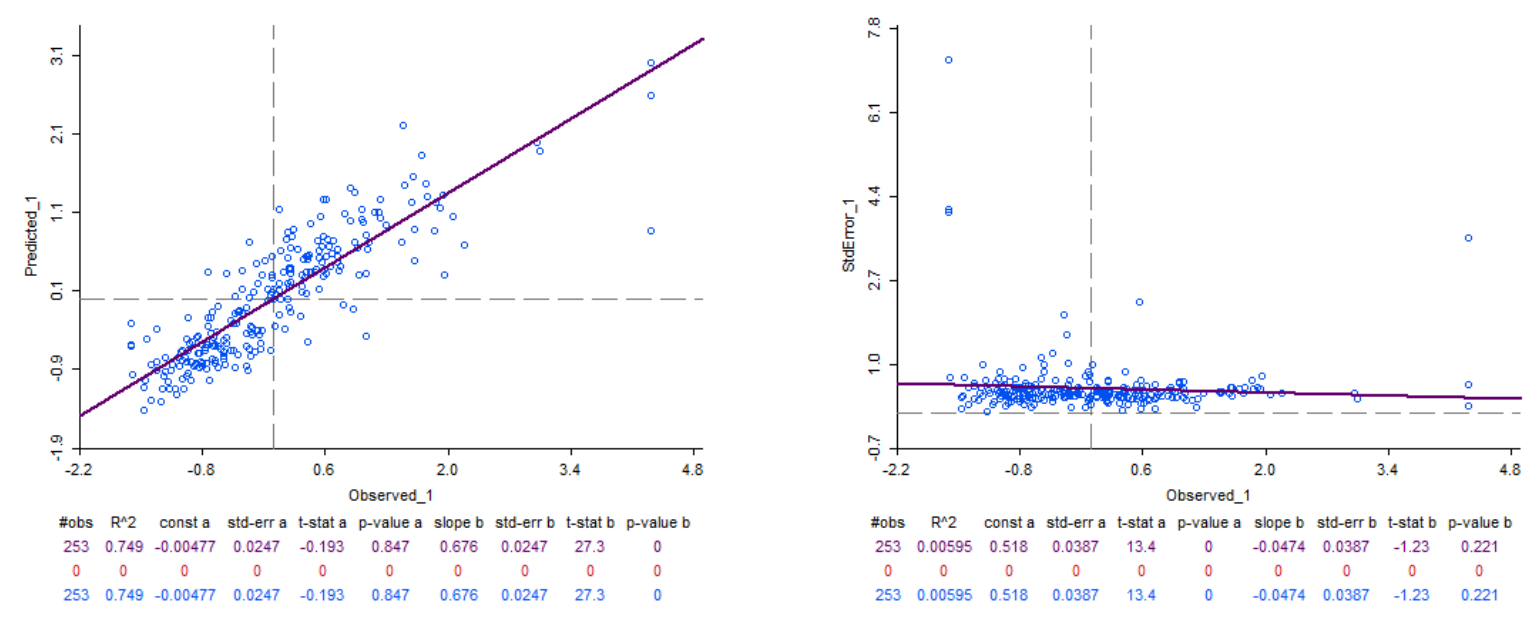

Figure 7. Cross-validation showing the fitting of the exponential model (a) and the plot of the standardised residuals (b)

Figure 8 shows the estimated fuel consumption map. 


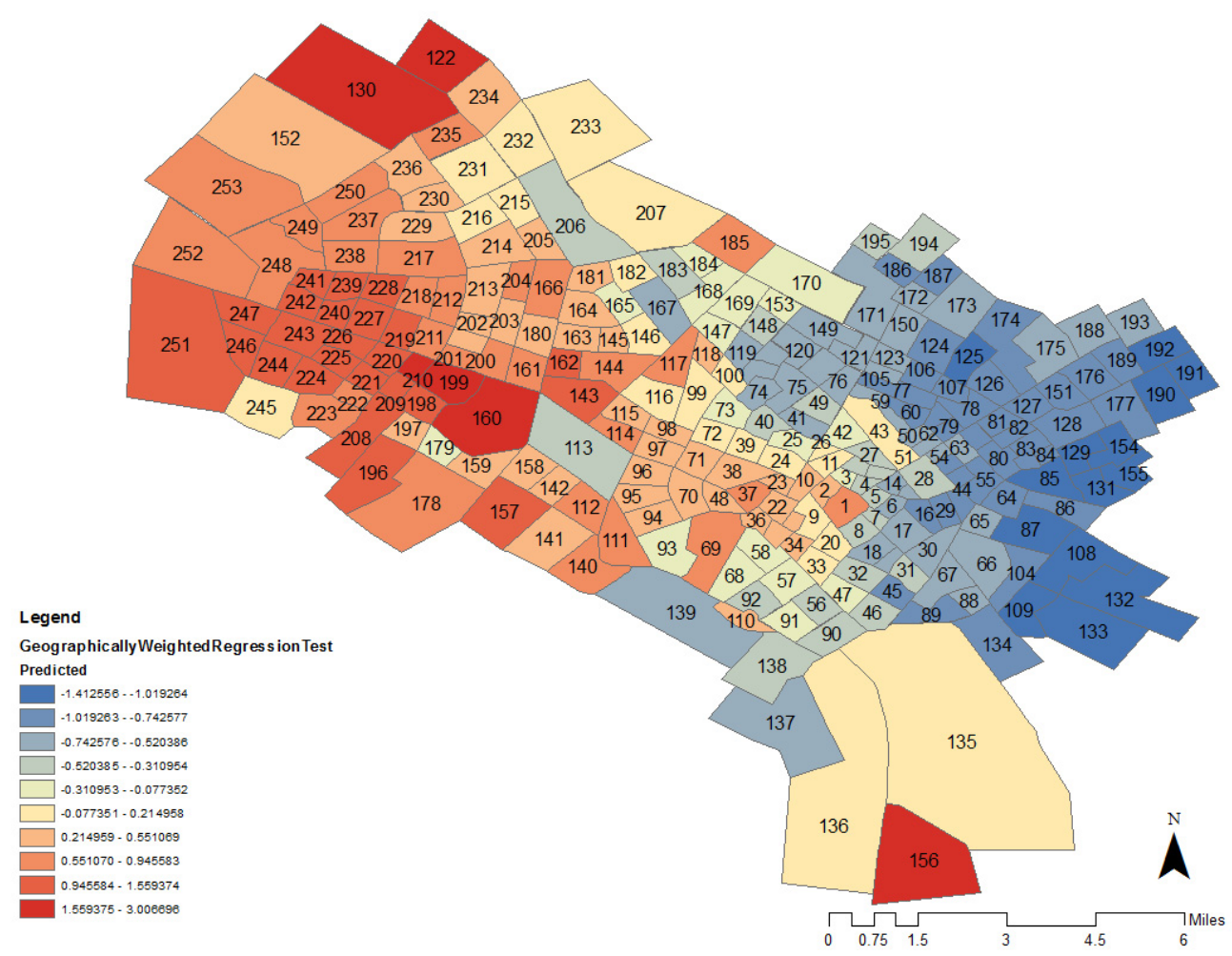

Figure 8. Final fuel consumption map obtained after a local regression model

\section{Discussion}

The fuel consumption is a complex multivariate phenomenon that is affected by different environmental factors, comprising VMT, mode choice, vehicle type choice, driving patterns and the built environment as well as travelers' socio-demographic characteristics .This work is one of the first attempts to study the correlations between the built environment and the fuel consumption in order to define the main effective variable using a modelling approach by means of the geographically weighted regression, a local spatial regression technique. More than 74000 trip data from the OD travel survey, combined with the built environment data from the literature and then aggregated to 253 traffic regions. The result used to assess the effects of the most dominant factors on the fuel consumption. The present method involves the construction and the comparison of global and local multivariate regression models, as well as autocorrelation indexes, as suitable tools to highlight the presence of local effects across space. The models were constructed starting from a conceptual model which included the following variables: average fuel consumption as dependent variables and population density, job density, land-use diversity, average block area, street density, distance to center, bus-line density, average income and average car ownership as explanatory variables.

OLS indicated that job density, land-use diversity, street density, bus-line density and average income were not significant variables in the model, and thus they were excluded.

GWR was used to study the strengths of the local relationships between the fuel consumption and the considered built environment factors. Results suggest that the spatial variations in the population density, average block size, distance to center a car ownership, significantly affect the fuel consumption. Local results identified areas where the model predicts well $(\mathrm{R} 2>0.5)$ and where it predicts poorly $(\mathrm{R} 2<0.5)$. Fotheringham et al. (1997) proposed that in the global models non complete dataset with missing information may cause spatial heterogeneity. Since complete datasets are difficult to obtain in the case of multivariate phenomena, the inclusion of the spatial information in local modelling techniques can significantly improve model predictability. However, the local GWR coefficients should be interpreted with caution, especially in the case of local multicollinearity of the explanatory variables; this increases the variances of the estimated regression coefficients and can invalidate conclusions about the relationships based on the estimated coefficients (Pasculli, Palermi, Sarra, Piacentini, \&Miccadei, 2014). Many works (Paez, Farber, \&Wheeler, 2011; Griffith, 2008; Wheeler, 2007) highlight that the lack of multicollinearity in the global regression models is not a guarantee for high performant GWR models. 
Mashhad shows a high degree of socio-demographic characteristics and travel attitude complexity which can only be properly represented by a very accurate and detailed dataset. For example, real income and real job have not been asked even in the census. This condition may explain why income was not significant in the global regression model. Maybe socio demographic characteristics and residential and travel preference data should be considered in more details which is not available now. These may provide hints about pivotal variables that may be ignored from the regression model.

\section{Conclusions}

The influence of the built environment and socio-economic characteristics on the energy consumption was examined with data aggregated from GCMR and analyzed through the SEM model. The article added empirical proof to the rare literature of the relationship between the built environments and socio-economic factors on the energy consumption in developing regions. The findings demonstrate that population density, building age, and floor area as the built environment driving factors had very low negative effects on the gasoline consumption, which is in contrast to the previous findings from researchers in both developing and developed cases studies. For the socio-economic driving factors, residence income and number of motorbikes had the highest positive effects on the energy consumption, which is consistent with previous findings.

With Increasing automobile usage and daily vehicle miles traveled (VMT), the shares of the transportation sector of the energy consumption and the air pollution are significant and increasing. This sector accounts for approximately 33 percent of total $\mathrm{CO}_{2}$ emissions from fossil fuel combustion, the largest share of any end-use economic sector (EIA, 2016).

Across Mashhad the second metropolitan of Iran, the fuel consumption is steadily rising. Between 2010 and 2015 total fuel consumption increased by almost 25\%, from 2590 to 3240 (Thousand liters).

A large number of previous studies have found the potential role of the built environment, and particularly of compact growth, in travel behavior and stabilizing global climates (Cervero\&Kockelman,1997; Crane, 2000; Ewing \& Cervero 2001; Ewing \& Cervero 2010; Cervero\&Murakami ,2010; Jahanshahi \& Jin ,2016). The influence of the built environment and socio-economic characteristics on the energy consumption is examined with data aggregated to 253 traffic regions of Mashhad and analyzed through the OLS and GWR model.

Our research findings are consistent with those of other researchers who claim that urban planning and city design should be part of the solution in reduction in the fuel consumption and consequently the air pollution. Although the study showed a moderately strong negative elasticity between population density and VMT/Cap, it has been found that the positive association between designs that are not pedestrian friendly (big block size) and distance to center as well as car ownership, moderated these effects.

Most of the existing studies investigate the connection of urban form and travel behavior using the global regression models which mostly conceal spatial autocorrelation and the complex associations among spatial variables. The use of GWR as a local spatial regression technique regarding the global regression models suggests the best estimate of the elasticity of the built environment and the fuel consumption. Density (population density $=-0.259335$ ), design (average block size $=0.147489$ ), accessibility (distance to center $=0.334953$ ) and socio-demographic characteristics (car ownership $=0.347878$ ). Although we measured diversity and destination accessibility, directly in our models, we believe that, for the most part, population density functioned as a surrogate, at least in part, of the other built environment variables.

By extension, this suggests that the largest energy consumption reductions would come from creating compact communities which have Land-use diversity and more walkable areas with pedestrian cycling infrastructure around all of the stations along transit lines.

Results of this testing fully corroborated body of evidence that the built environment play a key role in decreasing VMT and energy consumption. In order to enhance a sustainable urban plan, the socio-economic driving factors should be considered as one of the main element of energy consumption as well.

\section{References}

Akaike, H. (1974). A new look at the statistical model identification. IEEE Trans.Autom. Contr AC 19, $716 \mathrm{e} 723$.

Anderson, W., Kanaroglou, P., \& Miller, E. (1996). Urban Form, Energy and the Environment: A Review of Issues, Evidence, and Policy. Urban Studies, 33, 7-35. https://doi.org/10.1080/00420989650012095

Banister, D. (1997). Reducing the Need to Travel. Environment and Planning B-Planning \& Design, 24(3), 437449. https://doi.org/10.1068/b240437.

Barter, P. A. (2000). Compact cities: Sustainable urban forms for developing countries. In Jenks, M., \& Burgess, 
R. (Eds.), Transport Dilemmas in Dense Urban Areas: Examples from Eastern Asia (pp. 271-284). E \& FN Spon: London, UK.

Bennett, L., \& D'Acosta, J. (2010). Spatial statistics resources. ARC GIS BLOG.

Bhat, C. R., \& Sen, S. (2006). Household Vehicle Mod Holdings and Usage: An Application of the Multiple Discrete-continuous Extreme Value (MDCEV) Model. Transportation Research Part B: Methodologica, 40, 35-53. https://doi.org/10.1016/j.trb.2005.01.003

Boarnet, M., \& Sarmiento, S. (1998). Can Land-use Policy Really Affect Travel Behavior? A Study of the Link between Non-Work Travel and Land-use Characteristics. Urban Studies, 35, 1155-1169. https://doi.org/10.1080/0042098984538

Brian, S. (2008). Urban sprawl and air quality in large US cities. J. Env. Manag, 86, 688-698. https://doi.org/10.1016/j.jenvman.2006.12.034

Brownstone, D., \& Golob, T. F. (2009). The impact of residential density on vehicle usage and energy consumption. J. Urban Econ, 65, 91-98. https://doi.org/10.1016/j.jue.2008.09.002

Brundell-Freij, K., \& Ericsson, E. (2005). Influence of Street Characteristics, Driver Category and Car Performance on Urban Driving Patterns. Transportation Research Part D: Transportation and Environment, 10, 213-229. https://doi.org/10.1016/j.trd.2005.01.001

Brundson, C., Fotheringham, A. S., \& Charlton, M. E. (1999). Some notes on parametric significance tests for geographically weighted regression. Journal of Regional Science, 39, 497-524. https://doi.org/10.1111/0022-4146.00146

Brunsdon, C., Fotheringham, A. S., \& Charlton, M. (1996). Geographically weighted regression: A method for exploring spatial nonstationarity. Geographical Analysis, 28(4), 281-298. https://doi.org/10.1111/j.1538-4632.1996.tb00936.x

Brunsdon, C., Fotheringham, A. S., \& Charlton, M. (1998). Spatial nonstationarity and autoregressive models. Environment and Planning, 30, 957-973. https://doi.org/10.1068/a300957

Cao, X., Handy, S. L., \& Mokhtarian, P. L. (2006). The influences of the built environment and residential self-selection on pedestrian behavior: Evidence from Austin, TX. Transportation, 33(1), 1-20. https://doi.org/10.1007/s11116-005-7027-2

Cao, X., Mokhtarian, P. L., \& Handy, S. L. (2007b). Cross-sectional and Quasi-Panel Explorations of the Connection between the Built Environment and Auto Ownership. Environment and Planning A, 39(4), 830 847. https://doi.org/10.1068/a37437

Cao, X., Mokhtarian, P. L., \&Handy, S. L. (2007a). Do Changes in Neighborhood Characteristics Lead to Changes in Travel Behavior? A Structural Equations Model in Approach. Transportation, 34(5), 535-556. https://doi.org/10.1007/s11116-007-9132-x

Census of the Islamic Republic of Iran, 2011.

Census of the Islamic Republic of Iran, 2016.

Cervero, R. (1995). Planned communities, self-containment and commuting: A cross-national perspective. Urban Stud, 32, 1135-1161. https://doi.org/10.1080/00420989550012618

Cervero, R. (1996). Jobs-Housing Balance Revisited-Trends and Impacts in the San Francisco Bay Area. Journal of the American Planning Association, 62(4), 492-511. https://doi.org/10.1080/01944369608975714

Cervero, R., \& Kockelman, K. (1997). Travel Demand and the 3Ds: Density, Diversity, and Design. Transportation Research Part D: Transport and Environment, 2(3), 199-219. https://doi.org/10.1016/S1361-9209(97)00009-6

Cervero, R., \& Murakami, J. (2010). Effects of Built Environments on Vehicle Miles Traveled: Evidence from 370 US Urbanized Areas. Environment and Planning A, 42, 400-418. https://doi.org/10.1068/a4236

Ciotoli, G., Voltaggio, M., Tuccimei, P., Soligo, M., Pasculli, A., Beaubien, S. E., \& Bigi, S. (2016). Geographically weighted regression and geostatistical techniques to construct the geogenic radon potential map of the Lazio region: A methodological proposal for the European Atlas of Natural Radiation. Journal of Environmental Radioactivity, xxx, 1-21.

Cleveland, W. (1979). Robust locally weighted regression and smoothing scatter plots. J. Am. Stat. Assoc., 74, 
829-836. https://doi.org/10.1080/01621459.1979.10481038

Cliff, A., \& Ord, J. (1972). Testing for spatial autocorrelation among regression residuals. Geogr. Anal, 4, 267-284. https://doi.org/10.1111/j.1538-4632.1972.tb00475.x

Crane, R. (2000). The Influence of Urban Form on Travel: An Interpretive Review. Planning Literature, 15(1), 3-23. https://doi.org/10.1177/08854120022092890.

Crane, R., \& Crepeau, R. (1998). Does neighborhood design influence travel? A behavioral analysis of travel diary and GIS data. Transportation Research D, 3(4), 225-238. https://doi.org/10.1016/S1361-9209(98)00001-7

Ewing, R., \& Cervero, R. (2001). Travel and the Built Environment: A Synthesis. Transportation Research Record. Journal of the Transportation Research Board, 1780, 87-114. https://doi.org/ 10.3141/1780-10

Ewing, R., \& Cervero, R. (2010). Travel and the built environment. Journal of the American Planning Association, 76(3), 265-294. https://doi.org/10.1080/01944361003766766

Fang, H. A. (2008). A Discrete-Continuous Model of Households' Vehicle Choice and Usage, with an Application to the Effects of residential Density. Transportation Research Part B: Methodological, 42, 736-758. https://doi.org/10.1016/j.trb.2008.01.004

Fotheringham, A., Charlton, M., \& Brunsdon, C. (2001). Spatial variations in school performance: a local analysis using geographically weighted regression. Geogr.Environ. Model., 5(1), 43-66. https://doi.org/10.1080/13615930120032617

Fotheringham, S. A. (1997). Trends in quantitative methods I: stressing the local. Progress in Human Geography, 21, 88-96. https://doi.org/10.1191/030913297676693207

Fotheringham, S. A., Brunsdon, C., \& Charlton, M. E. (2002). Geographically Weighted Regression: The Analysis of Spatially Varying Relationships. Wiley, Chichester, U.K.

Fotheringham, S. A., Brunsdon, C., \& Charlton, M. E. (2009). Geographically weighted regression: software for GWR. Retrieved from http://ncg.nuim.ie/ncg/GWR/software.htm

Fotheringham, S., Brunsdon, C., \& Charlton, M. (2003). Geographically Weighted Regression: The Analysis of Spatially Varying Relationships. John Wiley\&Sons.

Frank, L. D., Bradley, M., Kavage, S., Chapman, J., \& Lawton, T. K. (2008). Urban Form, Travel Time, and Cost Relationships with Tour Complexity and Mode Choice. Transportation, 35, 37-54. https://doi.org/10.1007/s11116-007-9136-6

Frank, L. D., Stone, B., \& Bachman, Jr. W. (2000). Linking Land Use with Household Vehicle Emissions in the Central Puget Sound: Methodological Framework and Findings. Transportation Research Part D: Transportation and Environment, 5, 173-196. https://doi.org/10.1016/S1361-9209(99)00032-2

Frank, L., Martin, M., \& Schmid, T. (2004). Obesity Relationships with Community Design, Physical Activity, and Time Spent in Cars. American Journal of Preventive Medicine, 27, 8-96. https://doi.org/10.1016/j.amepre.2004.04.011

Gilbert, A., \& Chakraborty, J. (2011). Using geographically weighted regression for environmental justice analysis: Cumulative cancer risks from air toxics in Florida. Social Science Research, 40, 273-286. https://doi.org/10.1016/j.ssresearch.2010.08.006

Giuliano, G., \&Small, K. (1993). Is the Journey to Work Explained by Urban Structure? Urban Studies, 30, 1485-1500. https://doi.org/10.1080/00420989320081461

Griffith, D. A. (2008). Spatial-filtering-based contributions to a critique of geographically weighted regression (GWR). Environ. Plan, A 40, 2751-2769. https://doi.org/10.1068/a38218

Hamilton, L. C. (1992). Regression with Graphics. Brooks/Cole.

Hickman, R., Ashiru, O., \&Banister, D. (2010). Transport and climate change: simulating the options for carbon reduction in London. Transport Policy, 17(2), 110-125. https://doi.org/10.1016/j.tranpol.2009.12.002

Hickman, R., Seaborn, C., Headicar, P., \& Banister, D. (2009). Planning for Sustainable Travel. Summary Guide. London: Halcrowand Commission for Integrated Transport.

Ho, C. Q., \& Yamamoto, T. (2011). The role of attitudes and public transport service on vehicle ownership in Ho Chi Minh, Vietnam. In Proceedings of the Australasian Transport Research Forum, Adelaide, Australia, 28- 
30 September, 28-30.

Holden, E., \& Norland, I. T. (2005). Three challenges for the compact city as a sustainable urban form: Household consumption of energy and transport in eight residential areas in the greater Oslo Region. Urban Stud, 42, 2145-2166. https://doi.org/10.1080/00420980500332064

Huang, Y., \& Leung, Y. (2002). Analysing regional industrialisation in Jiangsu province using geographically weighted regression. J Geograph Syst, 4, 233-249. https://doi.org/10.1007/s101090200081

Hurvich, C. M., Simonoff, J. S., \& Tsai, C. L. (1998). Smoothing parameter selection in nonparametric regression using an improved Akaike information criterion. J. R.Stat. Soc.B, 60, 271-293. https://doi.org/10.1111/1467-9868.00125

Jahanshahi, K., \& Jin, Y. (2016). The built environment typologies in the UK and their influences on travel behaviour: new evidencethrough latent categorisation in structuralequation modelling. Transportation Planning and Technology, 39(1), 59-77. https://doi.org/10.1080/03081060.2015.1108083

Jarque, C., \& Bera, A. (1987). A test for normality of observations and regression residuals. Int. Stat. Rev, 55(2), 163-172. https://doi.org/10.2307/1403192

Kleinbaum, D. G., Kupper, L. L., Muller, K. E., \& Nizam, A. (1998). Applied Regression Analysis and Other Multivariate Methods (3rd ed.). Brooks/Cole, Belmont.

Krivoruchko, K. (2011). Spatial Statistical Data Analysis for GIS Users. Esri Press, Redlands, CA, 928.

Krivoruchko, K., Gribov, A., \& Krause, E. (2011). Multivariate areal interpolation for continuous and count data. Procedia Environ. Sci, 3, 14-19. https://doi.org/10.1016/j.proenv.2011.02.004

Krizek, K. (2003). Residential Relocation and Changes in Urban Travel: Does Neighborhood-Scale Urban Form Matter? J. Am. Plan. Assoc, 69, 265-281. https://doi.org/10.1080/01944360308978019

Levinson, D. M., \& Kumar, A. (1997). Density and the journey to work. Growth Change, 28, 147-172. https://doi.org/10.1111/1468-2257.00054

Mitchell, A. (2005). The ESRI Guide to GIS Analysis (Vol. 2). ESRI Press.

Mitchell, A. (2005). The ESRI Guide to GIS Analysis, Volume 2. ESRI Press, 2005 Geographically Weighted Regression: The Analysis of Spatially Varying Relationships by A. Stewart Fotheringham, Chris Brunsdon, Martin Charlton. 2003 Wiley.

Mitchell, R. B., \& Rapkin, C. (1954). Urban Traffic: A Function of Land Use. New York. Columbia University Press.

Musti, S., Kortum, K., \& Kockelman, K. (2010). Household Energy Use and Travel: Opportunities for Behavioral Change. Transportation Research Part D: Transportation and Environment, 16, 49-56. https://doi.org/10.1016/j.trd.2010.07.005

Nam, K., Lim, U., \& Kim, B. H. S. (2012). Compact or Sprawl for the sustainable urban form? Measuring the effect on travel behavior in Korea. Ann. Reg. Sci, 49, 157-173. https://doi.org/10.1007/s00168-011-0443-7

Newman, P., \& Kenworthy, J. R. (1999). Sustainability and Cities: Overcoming Automobile Dependence. Island Press. Retrieved from https://islandpress.org/book/sustainability-and-cities

Origin-destination report. Mashhad Traffic \& Transportation Organization 2000.

Osman, T., Arima, T., Divigalpitiya, P., \&Osman, M. (2016). The impact of Built Environment Characteristics on Metropolitans Energy Consumption: An Example of Greater Cairo Metropolitan Region. Buildings, 6(2), 12. https://doi.org/10.3390/buildings6020012

Paez, A., Farber, S., \&Wheeler, D. (2011). A simulation-based study of geographically weighted regression as a method for investigating spatially varying relationships. Environ. Plan. A, 43, 2992-3010. https://doi.org/10.1068/a44111

Pasculli, A., Palermi, S., Sarra, A., Piacentini, T., \& Miccadei, E. (2014). A modelling methodology for the analysis of radon potential based on environmental geology and geographically weighted regression. Environ. Model. Softw, 54, 165-181. https://doi.org/10.1016/j.envsoft.2014.01.006

Qui, X., \& Wu, S. (2013). Global and local regression analysis if factors of American college test (ACT) scores for public high schools in Missouri. Ann. Assoc. Am. Geogr., 101(1), 63-83.

Schweitzer, L., \& Zhou, J. (2010). Neighborhood Air Quality, Respiratory Health, and Vulnerable Populations in 
Compact and Sprawled Regions. J. Am. Plan. Assoc, 76, 363-371. https://doi.org/10.1080/01944363.2010.486623

Shen, Q. (2000). Spatial and Social Dimensions of Commuting. Journal of the American Planning Association, 66, 68-82. https://doi.org/10.1080/01944360008976085

Stead, D. (2001). Relationships between Land Use, Socioeconomic Factors, and Travel Patterns in Britain. Environment and Planning B-Planning \& Design, 28(4),499-528. https://doi.org/10.1068/b2677

Susilo, Y. O., \& Stead, D. (2012). Transport-related CO2 emissions: deconstructing the trends, Transition towards Sustainable Mobility: the Role of Instruments, Individuals and Institutions, Ashgate, Ashgate. Chap, 9, 165-186.

The Statistical Yearbook of Iran, 2016.

Tobler, W. R. (1970). A computer movie simulating urban growth in the Detroit region. Economic Geography, 46, 234-240. https://doi.org/10.2307/143141

Tu, J., \& Xia, Z. G. (2008). Examining partially varying relationships between land use and water quality using geographically weighted regression I: model design and evaluation. Sci Total Environ, 407, 358-378. https://doi.org/10.1016/j.scitotenv.2008.09.031

wheeler, D. C. (2007). Diagnostic tools and a remedial method for collinearity in geographically weighted regression. Environ. Plan. A 39, 2464e2481. https://doi.org/10.1068/a38325

Williams, K., Burton, E., \& Jenks, M. (2000) Achieving Sustainable Urban Form, E \& RN Spon: Abingdon, Oxon, UK.

Yamamoto, T. (2009). Comparative analysis of household car, motorcycle, and bicycle ownership between Osaka metropolitan area, Japan, and Kuala Lumpur, Malaysia. Transportation, 36, 351-366. https://doi.org/10.1007/s11116-009-9196-x

\section{Copyrights}

Copyright for this article is retained by the author(s), with first publication rights granted to the journal.

This is an open-access article distributed under the terms and conditions of the Creative Commons Attribution license (http://creativecommons.org/licenses/by/4.0/). 